\title{
Does plasma ANP participate in natriuresis induced by $\alpha-\mathrm{MSH}$ ?
}

\author{
D.L.W. Picanço-Diniz, \\ G. Ribeiro-Oliveira ${ }^{2}$, \\ A.L.V. Favaretto ${ }^{2}$, \\ J. Gutkowska ${ }^{3}$, \\ S.M. McCann ${ }^{4}$ and \\ J. Antunes-Rodrigues ${ }^{2}$
}

\author{
1Departamento de Fisiologia, Centro de Ciências Biológicas, \\ Universidade Federal do Pará, 66076-900 Belém, PA, Brasil \\ ${ }^{2}$ Departamento de Fisiologia, Faculdade de Medicina de Ribeirão Preto, \\ Universidade de São Paulo, 14049-900 Ribeirão Preto, SP, Brasil \\ ${ }^{3}$ Centre de Recherche Hôtel-Dieu de Montreal, Pavilion Marie-de-la-Ferre, \\ Montréal, Quèbec H2W 1T8, Canada \\ ${ }^{4}$ Neuropeptide Division, Department of Physiology, \\ The University of Texas Southwestern Medical Center, Dallas, Texas 75235, USA
}

\section{Correspondence \\ J. Antunes-Rodrigues \\ Departamento de Fisiologia \\ Faculdade de Medicina de \\ Ribeirão Preto, USP \\ Av. Bandeirantes, 3900 \\ 14049-900 Ribeirão Preto, SP \\ Brasil}

Presented at the International Symposium "Neuroendocrine Control of Body Fluid Homeostasis", Ribeirão Preto, SP, Brasil,

August 17-20, 1996.

Research supported by FAPESP (Nos. 91/0567-0 and 94/3805-7) and CNPq (Nos. 50167/91-7 and 521593/94-8).

$\ldots \ldots \ldots \ldots \ldots \ldots \ldots$

Received November 29, 1996 Accepted January 6, 1997

\begin{abstract}
$\alpha$-Melanocyte-stimulating hormone ( $\alpha$-MSH; 0.6 and $3 \mathrm{nmol}$ ) microinjected into the anteroventral region of the third ventricle (AV3V) induced a significant increase in diuresis without modifying natriuresis or kaliuresis. Intraperitoneal (ip) injection of $\alpha$-MSH ( 3 and 9.6 $\mathrm{nmol}$ ) induced a significant increase in urinary sodium, potassium and water excretion. Intraperitoneal ( 3 and $4.8 \mathrm{nmol}$ ) or $i v$ ( 3 and $9.6 \mathrm{nmol}$ ) administration of $\alpha-\mathrm{MSH}$ did not induce any significant changes in plasma atrial natriuretic peptide (ANP), suggesting that the natriuresis, kaliuresis and diuresis induced by the systemic action of $\alpha-\mathrm{MSH}$ can be dissociated from the increase in plasma ANP. These preliminary results suggest that $\alpha$-MSH may be involved in a $\gamma$-MSHindependent mechanism of regulation of hydromineral metabolism.
\end{abstract}

Key words

- $\alpha-M S H$

- AV3V

- ANP

- Natriuresis

- Kaliuresis

- Diuresis

\section{Introduction}

$\alpha$-Melanocyte-stimulating hormone ( $\alpha$ $\mathrm{MSH})$ is a peptide derived from proopiomelanocortin (POMC), a precursor protein that contains the amino acid sequences of other peptides acting on salt and water balance in the organism, including $\beta-$ and $\gamma$-MSH (1).

The participation of $\alpha$-MSH in the regulation of mineral metabolism has been discussed by many investigators (2). Water deprivation for $12 \mathrm{~h}$ and oral (3) or intravenous (iv) injection of hypertonic $\mathrm{NaCl}$ solutions produced a marked depletion of pituitary MSH, suggesting a compensatory secretion in response to salt concentration in the organism. Intraperitoneal (ip) injections of $\alpha$ $\mathrm{MSH}$ exhibited a natriuretic and kaliuretic effect in intact (4) hypophysectomized or adrenalectomized (5) water-loaded rats, indicating an independent action of pituitary and adrenal glands and suggesting its direct intervention at the renal level. An antidiuretic effect was observed after ip injection of $\alpha$-MSH into water-loaded rats, but the authors suggested that this effect resulted from lysine-vasopressin contamination in the preparation (6).

The participation of atrial natriuretic peptide (ANP) directly at the renal level and dependence on renal nerve activity are two possible mechanisms suggested for the natriuresis induced by $\gamma$-MSH. However, only few studies on the mechanisms involved in $\alpha$-MSH effects on salt and water metabolism have been reported (2). 
In the present study we examined the possibility of a modulatory action of $\alpha-\mathrm{MSH}$ on hydromineral metabolism by a $\gamma$-MSHindependent mechanism of action.

\section{Material and Methods}

Adult male Wistar rats (230-260 g body weight) from our animal facilities, housed in individual cages under controlled light (14-h light, 10-h dark) and temperature conditions $\left(23-25^{\circ} \mathrm{C}\right)$ with free access to food and water, were used.

For the experiments the animals were divided into three experimental groups: i) rats with chronically indwelling AV3V cannulae were subjected 5 days later to $\alpha-\mathrm{MSH}$ (0.6 and $3.0 \mathrm{nmol}$ ) microinjection to study its effect on sodium, potassium and water excretion. ii) Intact rats were injected $i p$ with $\alpha$-MSH (3.0 and $9.6 \mathrm{nmol}$ ) to study its effect on sodium, potassium and water excretion. iii) Intact or jugular-cannulated rats were injected ip (3.0 and $4.8 \mathrm{nmol}$ ) or $i v$ (3.0 and $9.6 \mathrm{nmol}$ ) with $\alpha-\mathrm{MSH}$, respectively, to study its effect on plasma atrial natriuretic peptide levels. The rats were sacrificed prior to $(0$ $\min$ ) and 5 or $15 \mathrm{~min}$ after $\alpha$-MSH injection.

\section{Experimental procedures}

Under anesthesia with tribromoethanol $(2.5 \mathrm{mg} / 100$ gbody weight; T4840-2; Aldrich, Milwaukee, WI), a stainless steel cannula (0.7 mm OD, $13 \mathrm{~mm}$ length) was stereotaxically implanted into the $\mathrm{AV} 3 \mathrm{~V}$ according to a technique previously described (7), using the Paxinos and Watson stereotaxic coordinates (8). The animals were then handled daily and trained for gavage to reduce any stress associated with these experimental procedures.

Five days after surgery, the rats were fasted for $14 \mathrm{~h}$ before the experiment with free access to water. On the next morning, each rat received a load of tepid tap water (5\% body weight) by gavage, and was placed in an individual metabolic cage without food or water. Urine passed through the funnel at the bottom of the cage into a graduated centrifuge tube. Urinary volume (reported as $\mu \mathrm{l}$ $\min ^{-1} 100 \mathrm{~g}$ body weight ${ }^{-1}$ ) was collected immediately before and 20, 60, and $120 \mathrm{~min}$ after drug microinjection into the AV3V (experiment I) or ip (experiment II) injection.

$\alpha-M S H$ (7251; Peninsula Laboratories, Belmont, CA) was injected into the AV3V $(1 \mu \mathrm{l})$ through a stainless steel dental cannula (0.31 mm OD, $14 \mathrm{~mm}$ length) connected to a $10-\mu \mathrm{l}$ Hamilton microsyringe by a polyethylene tube (PE 10). Intraperitoneal $\alpha$-MSH injections $(0.2 \mathrm{ml}$; experiment II) were performed through a $1-\mathrm{ml}$ syringe into the abdominal region. Saline vehicle $(0.15$ $\mathrm{M} \mathrm{NaCl}$ ) was used as control for all experiments. Intravenous $\alpha$-MSH injections $(0.2$ $\mathrm{ml}$; experiment III) were performed through a silastic cannula implanted (1 day before) into the jugular vein connected to a polyethylene tube (PE 50), as previously described (9). Routine histological procedures were done to localize the sites where the cannulae were implanted. After the experiments, all animals were killed under ether anesthesia and the brains were removed and fixed in $10 \%$ formol. Twenty- $\mu$ m thick frontal paraffin sections were stained by the Nissl technique.

\section{Measurements}

Each urine sample was analyzed for sodium and potassium concentrations $(\mu \mathrm{Eq}$ $\min ^{-1} 100 \mathrm{~g}$ body weight $^{-1}$ ) using a Micronal flame photometer (model B262).

For ANP determination, the animals were decapitated and trunk blood $(2 \mathrm{ml})$ was collected into tubes cooled in crushed ice. The tubes contained the following proteolytic enzyme inhibitors: $2 \mathrm{mg}$ EDTA, $20 \mu \mathrm{l} 1 \mathrm{mM}$ phenylmethylsulfonyl fluoride (Sigma, P7626), and $20 \mu 1500 \mu \mathrm{M}$ pepstatin A (Sigma, P-4265). The collected samples were centrifuged at low speed for $20 \mathrm{~min}$, and the 
plasma was stored at $-70^{\circ} \mathrm{C}$. Immunoreactive ANP was extracted from $1 \mathrm{ml}$ of plasma by heat-activated Vycor glass (No. 7930, Mesh 140; Corning, New York), and the lyophilized residue was stored at $-70^{\circ} \mathrm{C}$. Each sample was resuspended in $400 \mu \mathrm{l}$ ANP buffer (50 $\mathrm{mM}$ potassium phosphate, $\mathrm{pH}$ 7.4, containing $0.15 \mathrm{M} \mathrm{NaCl}, 0.1 \%$ bovine serum albumin (Sigma No. A-7888), 0.1\% Triton X100 , and $0.02 \% \mathrm{NaN}_{3}$ ), and aliquots of 50 and $100 \mu \mathrm{l}$ were taken in duplicate for radioimmunoassay (10).

\section{Statistical analysis}

The statistical analysis of the data was performed by GBSTAT computer program. Data are reported as means \pm SEM. Analysis of variance (ANOVA) was used for statistical evaluation. A $P$ value less than 0.05 was considered to be significant.

\section{Results}

Effect of central (AV3V) or systemic (ip) injection of $\alpha$-MSH on natriuresis, kaliuresis and diuresis (experiments I and II)

Figure $1 \mathrm{~A}$ and $1 \mathrm{~B}$ shows that microinjections of $\alpha-\mathrm{MSH}$ into the AV3V did not induce changes in sodium or potassium excretion. On the other hand, a significant increase in urine outflow occurred $20 \mathrm{~min}$ after microinjection of $0.6 \mathrm{nmol} \alpha-\mathrm{MSH}$ $(175 \%)$ and $3 \mathrm{nmol}(151 \%)$ into the AV3V (Figure 1C).

$\alpha-\mathrm{MSH}$ at the 3-nmol dose induced a significant increase in sodium excretion 20 $\min (184 \%)$ and $60 \mathrm{~min}(84 \%)$ after ip administration. $\alpha-\mathrm{MSH}$ at the 9.6-nmol dose induced a $176 \%$ and $75 \%$ increase in sodium excretion at 60 and $120 \mathrm{~min}$, respectively, under the same experimental conditions (Figure 2A). A two-phase effect on potassium excretion was observed after ip administration of $\alpha-\mathrm{MSH}$ at the 3-nmol dose. This dose induced an increase at $20 \mathrm{~min}(61 \%)$ and no effect at $60 \mathrm{~min}$ and a later significant decrease at $120 \mathrm{~min}(55 \%)$ in potassium excretion. No changes in potassium excretion were observed after $\alpha-\mathrm{MSH}$ administration at the

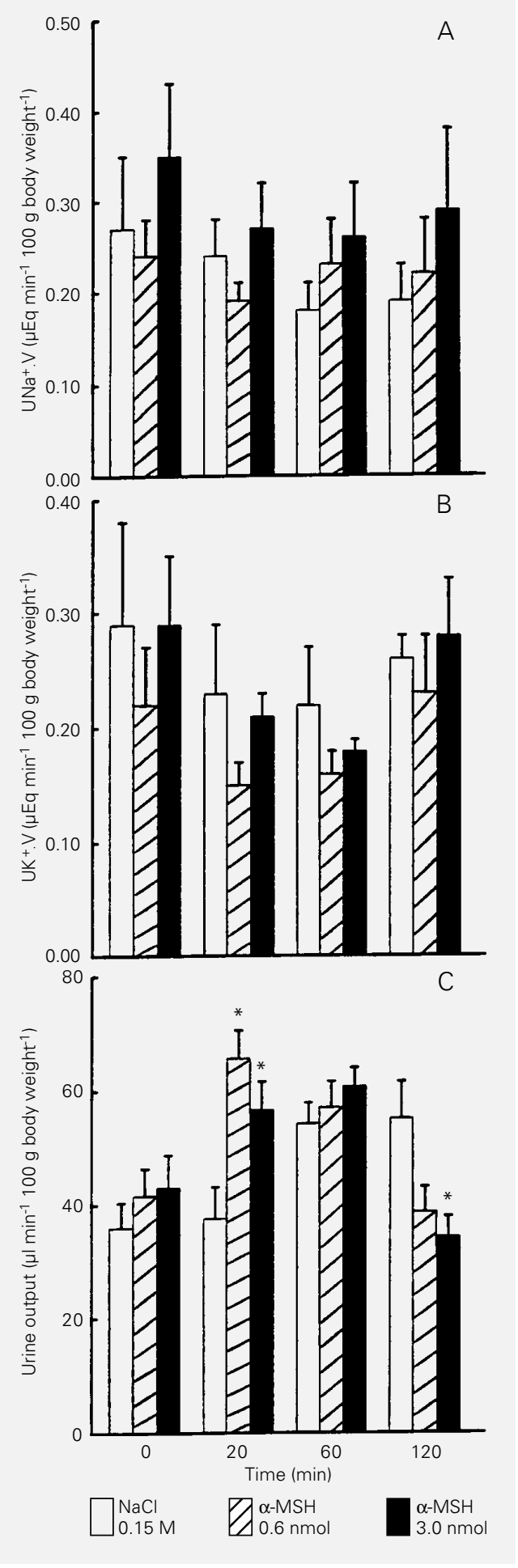

Figure 1 - Effects of microinjection of $\alpha-\mathrm{MSH}$ into the AV3V on sodium (A), potassium (B) and urine output (C) in water-loaded rats. Urine samples were collected before and 20,60, and 120 min after microinjection of the peptide into the AV3V. $\alpha-$ MSH (0.6 and $3.0 \mathrm{nmol}$ ) was delivered in $1.0 \mu \mathrm{l}$ saline. Data are reported as means \pm SEM for 8 to 14 animals per group. $\mathrm{UNa}^{+}$.V or UK+. $\mathrm{V}=$ Sodium or potassium excretion expressed as the product of concentration of the ion and urine flow per min (V). ${ }^{*} P<0.05$ compared to control group (ANOVA). 
9.6-nmol dose (Figure 2B). Figure 2C shows that ip injection of the peptide $(3 \mathrm{nmol})$ induced a significant increase in urine output at $20(86 \%)$ and $60 \mathrm{~min}(41 \%)$. A two-
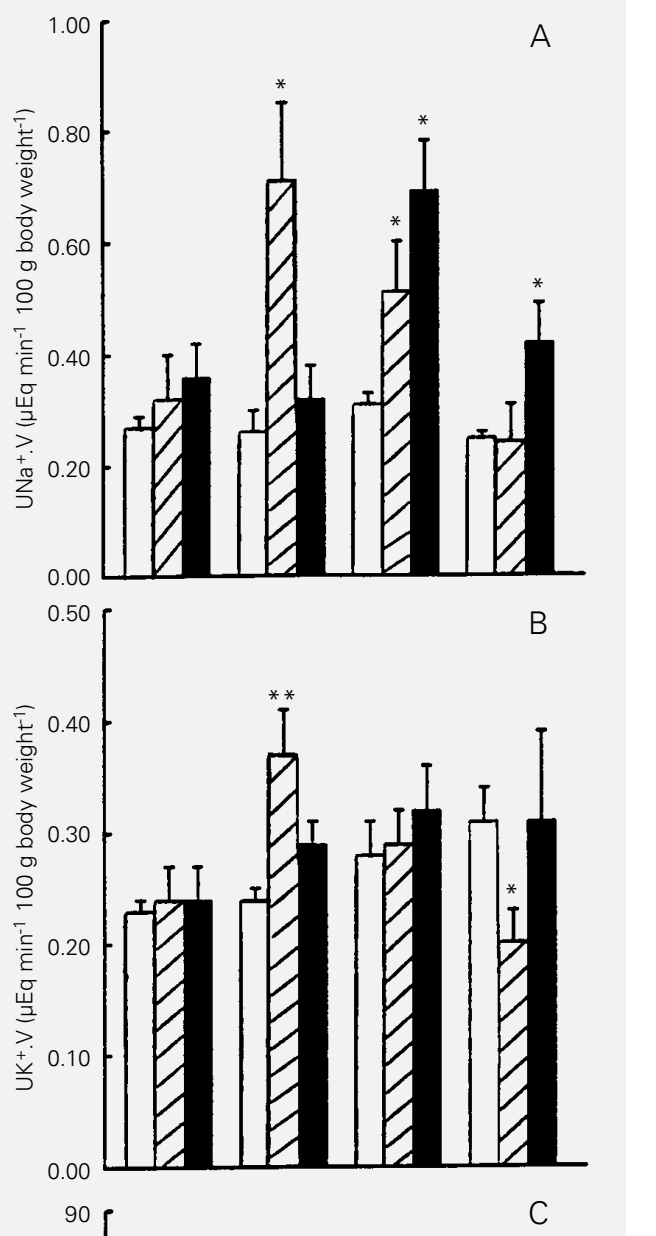

Figure 2 - Effects of ip administration of $\alpha-\mathrm{MSH}$ on sodium (A), potassium (B) and urine output (C) in water-loaded rats. Urine samples were collected before and 20,60, and 120 min after injection. $\alpha-\mathrm{MSH}(3.0$ and 9.6 nmol) was delivered in $200 \mu \mathrm{l}$ saline. Data are reported as means \pm SEM for 5 to 7 animals per group. ${ }^{*} \mathrm{P}<0.05$, ${ }^{*} \mathrm{P}<0.01$ compared to control (ANOVA). phase effect on urine output was observed after ip injection of $\alpha-\mathrm{MSH}$ at the 9.6-nmol dose. A significant increase was observed at $20 \mathrm{~min}(78 \%)$, no effect at $60 \mathrm{~min}$ and a significant decrease (52\%) at $120 \mathrm{~min}$ (Figure $2 \mathrm{C}$ ).

Effect of systemic (iv or ip) injection of $\alpha$ MSH on plasma ANP levels (experiment III)

Table 1 shows that intraperitoneal injections of $\alpha-\mathrm{MSH}$ ( 3 and $4.8 \mathrm{nmol}$ ) did not affect ANP levels throughout the experimental periods (5 and $15 \mathrm{~min}$ ). Similar results were obtained with intravenous injections of 3 and 9.6 nmol of $\alpha$-MSH (data not shown).

\section{Discussion}

Although it has been known for many years that systemic administration of $\alpha$-MSH induces an increase in sodium and potassium urinary excretion (4-6), the mechanism of these effects remains unknown. The putative participation of the central nervous system in these effects was investigated in the present study. Our results showed that $\alpha$ $\mathrm{MSH}$ administration into the AV3V at the doses of 0.6 and $3 \mathrm{nmol}$ induced an increase in urine outflow but no effect on natriuresis or kaliuresis (Figure 1A-C). These data suggest a positive and independent $\alpha$-MSH regulation of urine outflow at the AV3V level, since a systemic effect of central administration would be improbable because, under these experimental conditions, no changes in natriuresis or kaliuresis were observed. Probably an inhibitory influence on vasopressin secretion via inhibition of cholinergic and angiotensinergic neurons in the AV3V may explain the data observed (11).

Our results also show that plasma ANP is not involved in the increase of water and electrolyte excretion induced by systemic $\alpha$ MSH administration because ip injection of $\alpha$-MSH (3 and $4.8 \mathrm{nmol}$ doses) did not induce changes in plasma ANP levels during 
the experimental period analyzed (Table 1). The natriuretic effect of $\alpha$-MSH has also been described in hypophysectomized or adrenalectomized rats, leading the authors to suggest that the kidneys were the most probable site of action of $\alpha$-MSH (5). However, direct effects of $\alpha-\mathrm{MSH}$ on renal function and ANP secretion have not been well explored. In contrast, several lines of evidence indicate that $\gamma-\mathrm{MSH}$-induced natriuresis may be mediated by ANP or occur by a direct action of the peptide at the renal level, being dependent on renal nerve activity (2). The uncorrelated increase in $\alpha$-MSH-induced natriuresis with plasma ANP hereby reported suggests that this peptide may have mechanisms of action different from those of $\gamma$ $\mathrm{MSH}$.

The diuretic effect observed after ip administration of $\alpha$-MSH ( $3 \mathrm{nmol}$ ) in the present study is contrary to that observed by other investigators who suggested that antidiuresis evoked by large doses of $\alpha$-MSH may be caused by contamination with lysinevasopressin, since the preparation supplied was reported to contain $0.1 \mathrm{mU}$ of pressor activity per $\mu \mathrm{g}$ (6). The diuretic effect of $\alpha$ MSH may result from a direct action at the renal level by inhibition of tubular sodium reabsorption (2) or by a central inhibition of vasopressin secretion.

\section{References}

1. Eipper BA \& Mains RE (1980). Structure and biosynthesis of pro-adrenocorticotropin/endorphin and related peptides. Endocrine Reviews, 1: 1-27.

2. Valentin JP, Wiedemann E \& Humphreys $\mathrm{MH}$ (1993). Natriuretic properties of melanocyte-stimulating hormones. Journal of Cardiovascular Pharmacology, 22: S114S118.

3. Kastin AJ (1967). MSH and vasopressin activities in pituitary of rats treated with hypertonic saline. Federation Proceedings, 26: 255 (Abstract)

4. Orias R \& McCann SM (1970). Natriuretic effect of $\alpha$-MSH in the water-loaded rat. Proceedings of the Society for Experimental Biology and Medicine, 133: 469-474.
Table 1 - Plasma ANP concentration (pg/ml) before and 5 and 15 min after ip injection of $\alpha-\mathrm{MSH}$

Animals were decapitated and trunk blood was collected into cooled tubes with proteolytic enzyme inhibitors. Immunoreactive ANP was extracted from $1.0 \mathrm{ml}$ of plasma with Vycor and assayed by RIA. $\alpha$-MSH ( 3.0 and $4.8 \mathrm{nmol}$ ) was delivered in $200 \mu \mathrm{l}$ saline. The number of animals is given in parentheses.

\begin{tabular}{lcccc}
\hline & $\begin{array}{c}\text { Dose } \\
\text { (nmol) }\end{array}$ & \multicolumn{4}{c}{ Time $(\mathrm{min})$} \\
\cline { 3 - 5 } & & 0 & 5 & 15 \\
\hline Basal & - & $\begin{array}{c}39.73 \pm 4.67 \\
(13)\end{array}$ & - & - \\
& & - & $28.37 \pm 6.01$ & $30.11 \pm 4.99$ \\
$\alpha-\mathrm{MSH}$ & 3.0 & & $(9)$ & $(7)$ \\
& & - & $33.10 \pm 9.53$ & $37.37 \pm 10.52$ \\
$\alpha-\mathrm{MSH}$ & 4.8 & & $(9)$ & $(4)$
\end{tabular}

In conclusion, our data indicate that $\alpha$ MSH may induce diuresis by a central action, and natriuresis, kaliuresis and diuresis by a systemic action. These effects on sodium and potassium excretion seem not to be mediated by changes in plasma ANP. These preliminary results suggest that $\alpha-\mathrm{MSH}$ may be involved in a $\gamma$-MSH-independent mechanism of regulation of hydromineral metabolism.

\section{Acknowledgments}

We thank Marina Holanda and Maria Valci Aparecida dos Santos Silva for technical assistance.
5. Orias R \& McCann SM (1972). Natriuretic effect of alpha melanocyte stimulating hormone ( $\alpha-\mathrm{MSH})$ in hypophysectomized or adrenalectomized rats. Proceedings of the Society for Experimental Biology and Medicine, 139: 872-876.

6. Orias R \& McCann SM (1972). Natriuresis induced by alpha and beta melanocyte stimulating hormone (MSH) in rats. Endocrinology, 90: 700-706.

7. Antunes-Rodrigues $J$ \& McCann SM (1970). Water, sodium chloride, and food intake induced by injections of cholinergic and adrenergic drugs into the third ventricle of the rat brain. Proceedings of the Society for Experimental Biology and Medicine, 133: 1464-1470.
8. Paxinos G \& Watson C (1986). The Rat Brain in Stereotaxic Coordinates. 2nd edn. Academic Press, Orlando.

9. Harms PG \& Ojeda SR (1974). A rapid and simple procedure for chronic cannulation of the rat jugular vein. Journal of Applied Physiology, 36: 391-392.

10. Gutkowska J (1987). Radioimmunoassay for atrial natriuretic factor. Nucleotide Medical Biology, 14: 323-331.

11. Hoffman WE, Phillips MI \& Schmid PG (1977). Antidiuretic hormone release and the pressor response to central angiotensin II and cholinergic stimulation. Neuropharmacology, 16: 463-472. 